American Journal of Agricultural and Biological Sciences 6 (2): 256-260, 2011

ISSN 1557-4989

(C) 2011 Science Publications

\title{
Forest Structure Assessment of a Rehabilitated Forest
}

\author{
${ }^{1}$ Roland Kueh Jui Heng, ${ }^{3}$ Nik Muhamad Abd. Majid, ${ }^{1}$ Seca Gandaseca, \\ ${ }^{2}$ Osumanu Haruna Ahmed, ${ }^{1}$ Silvester Jemat and ${ }^{1}$ Melvin Ku Kin Kin \\ ${ }^{1}$ Department of Forestry Science, \\ ${ }^{2}$ Department of Crop Science, Faculty of Agriculture and Food Sciences, \\ University Putra Malaysia, Bintulu Sarawak Campus, 97008 Bintulu, \\ ${ }^{3}$ Department of Forest Management, Faculty of Forestry \\ Universiti Putra Malaysia, 43400 Serdang, Selangor, Malaysia
}

\begin{abstract}
Problem statement: Forest structure assessment provides information on forest succession, dynamics, biodiversity and health which are important but only few information is available on rehabilitated forest. The objective of this study was to assess the forest structure of selected age stands at a rehabilitated forest situated in Universiti Putra Malaysia Bintulu Sarawak Campus, Sarawak, Malaysia. Approach: Four $20 \times 20 \mathrm{~m}$ plots were established in stands planted in 1991, 1999, 2008 and an adjacent natural regenerating secondary forest ( \pm 22 years) and all stands were measured for Diameter Breast Height (DBH) and height and identified. Results: Forest structural analysis showed better performance in the structural characteristics mainly the mean basal area $(61 \%)$, mean Dbh $(56 \%)$ and mean height $(60 \%)$ of the trees as compared to the adjacent natural regenerating secondary forest. Conclusion: It can be concluded that after 18 years, rehabilitated forest using accelerating natural regeneration technique showed better structural dimension. This can help to promote the reforestation and restoration activities on degraded forest. Overall, rehabilitated forest areas have yet recovered in terms of size and height.
\end{abstract}

Key words: Forest structure, forest rehabilitation, accelerating natural regeneration, tropical succession, Diameter Breast Height (DBH), adjacent plot, diameter class, structural characteristics, biodiversity conservation, quasi-natural forests, structure assessment

\section{INTRODUCTION}

One of the most global pressing environmental concerns is forest degradation due to anthropogenic activities (Verchot and Petkova, 2009). Restoring these forests or secondary forests are of paramount importance as there has been increasing attention towards these forests as the sustainable use of these resources can provide products and services for mankind. These require some knowledge on the forest dynamics which are influenced by succession processes in the forest ecosystem.

There are considerable work has been done on the dynamics of secondary succession immediately following clearance and burning and the early stages of tropical succession are well documented. In addition to that, there are many researchers who focused on the structural and compositional aspects of tropical forest, be it in primary or secondary forest such as Alfred et al. (2010), Ainuddin and Goh (2010). However, there is a lack of information on rehabilitated forests from the aspect of the structure, in particular.

From the aspect of biodiversity conservation and forest health, it is important to know how these rehabilitated forests compare with primary forests in terms of structure. In natural succession processes, it is expected that regenerating secondary forests will continue to increase in their similarity to primary forests. The estimated time taken for complete succession has been estimated at 50-80 years (Brown and Lugo, 1990), 150-200 years (Richards, 1996), 300-500 years (Miyawaki, 1999) and centuries.

Several hundred years of natural succession, regeneration and recovery is too long. However, human intervention by using ecological restoration of degraded forest based on the system of natural forests can build multi strata quasi-natural forests in 40-50 years for Southeast Asia forest (Miyawaki, 1999). This technique is called accelerating natural regeneration. The objective of this study was to assess the forest structure

Corresponding Author: Roland Kueh Jui Heng, Faculty of Agriculture and Food Sciences, Universiti Putra Malaysia,

Bintulu Sarawak Campus, 97008 Bintulu, Sarawak, Malaysia 
at selected age stands at the UPM-Mitsubishi Corporation Forest Rehabilitation Project site situated in Universiti Putra Malaysia Bintulu Sarawak Campus, Sarawak, Malaysia.

\section{MATERIALS AND METHODS}

Study sites: The study was conducted at a rehabilitated forest in Universiti Putra Malaysia, Bintulu Sarawak Campus and Sarawak, Malaysia. It is located about 600 kilometers Northeast of Kuching, latitude $03^{\circ} 12^{\prime} \mathrm{N}$, longitude $113^{\circ} 02^{\prime} \mathrm{E}$ and $50 \mathrm{~m}$ above sea level. Research plots of $20 \times 20 \mathrm{~m}$ size were established at stands established in 1991 (Plot 1991), 1999 (Plot 1999) and 2008 (Plot 2008) of mix-species stand and an adjacent plot in natural regenerating secondary forest at Bukit Nyabau ( \pm 22 years; Plot NF).

Data collection: All trees in the plots were measured for their Diameter Breast Height (DBH) and height. Data collected was analyzed on stand in each plot. The stand data was analyzed for $\mathrm{DBH}$, height distribution and basal area distribution.

Statistical analysis: Comparisons were made between the study plots on DBH, height and basal using t-test with each plot considered as an independent replicate. Forest diameter size class structure was compared using a Pearson chi-square test ( $\lambda^{2}$-test), again pooling the data for each study site. All statistical analyses were carried out using SPSS Version 16.0 statistical package software.

\section{RESULTS}

Stocking and diameter: Stocking of trees in Diameter Class less than $10.0 \mathrm{~cm}$ in Plot 1991, remained the highest comprising about $75 \%$ of the total trees. The frequency distribution of diameter classes for all trees showed a negative exponential form having a steep slope for the first few diameter class (Fig. 1). The average Dbh in Plot 1991 was $8.16 \mathrm{~cm}$ with a basal area of $1.56 \mathrm{~m}^{2} 0.04 \mathrm{~h}^{-1}$ (Table 1). In Plot 1999, about $90 \%$ of trees were in the Diameter Class 0.0-10.0 cm.

In Plot 1999, the average Dbh was $6.00 \mathrm{~cm}$ while Plot 2008 was $0.76 \mathrm{~cm}$ whereas in Plot 2008, all of the trees are still small in size of less than $10.0 \mathrm{~cm}$ diameter. The basal area for Plot 1999 was $0.91 \mathrm{~m}^{2} 0.04$ $\mathrm{h}^{-1}$ while for Plot 2008, it was $0.02 \mathrm{~m}^{2} 0.04 \mathrm{~h}^{-1}$. In Plot $\mathrm{NF}$, stocking of trees in Diameter Class less than 10.0 $\mathrm{cm}$ remained the highest comprising about $93.8 \%$ of the total trees. The Diameter Class structure was compared using a Pearson Chi-square test $\left(\lambda^{2}\right.$-test) with the data pooled for each study plot. There were significant differences between all the study plots in terms of number of stem in each Diameter Class structure $\left(\lambda^{2}=\right.$ $\left.1.2 \times 10^{-2}\right)$ and in terms of stem percentage $\left(\left(\lambda^{2}=39.19\right.\right.$; Fig. 1). All study plots having more than $80 \%$ of trees concentrated in Diameter Class 0-10 cm except for Plot $1991(75 \%)$.

Basal area: The mean basal area of Plot 1991 was $61 \%$ of Plot NF with significant higher by using independent t-test with unequal variance. Stand in Plot 1991 had the most area coverage while the least was in Plot 2008. The mean basal area $\left(\mathrm{m}^{2}\right.$ plot $\left.^{-1}\right)$ distribution among study plots are a shown in Table 1.The mean Dbh of Plot 1999 and 1991 were 35 and 56\%, respectively of the Plot NF with significant differences, despite Plot NF having the biggest diameter tree $(59.80 \mathrm{~cm})$ in the study plot and high number of tree density (546). Plot 2008 has the smallest mean diameter of trees as compared to all the study plots while Plot 1991 has the largest mean diameter. The mean Dbh $(\mathrm{cm})$ distribution among the study plots are shown in Table 1 .

Table 1: Basal Area $\left(\mathrm{m}^{2} 0.04 \mathrm{~h}^{-1}\right)$ and Dbh $(\mathrm{cm})$ and height $(\mathrm{m})$ range in the study plots

\begin{tabular}{lllll}
\hline & Plot 2008 & Plot 1999 & Plot 1991 & Plot NF \\
\hline $\begin{array}{l}\text { Basal area } \\
\left(\mathrm{m}^{2} 0.04 \mathrm{~h}^{-1}\right)\end{array}$ & 0.02 & 0.80 & & 1.56 \\
Mean* & $0.05^{-3} \pm 0.3 \times 10^{-5}$ & $0.35 \times 10^{-2} \pm 0.2 \times 10^{-3}$ & $0.76 \times 10^{-2} \pm 0.8 \times 10^{-3}$ & $0.30 \times 10^{-2} \pm 0.7 \times 10^{-3}$ \\
& $\left(7.0 \times 10.0^{-7}-0.54 \times 10.0^{-3}\right)$ & $\left(0.5 \times 10.0^{-4}-0.02\right)$ & $\left(0.1 \times 10.0^{-3}-0.09\right)$ & $\left(0.1 \times 10.0^{-4}-0.28\right)$ \\
Dbh $(\mathrm{cm})$ & & & & \\
Mean* & $0.76 \pm 0.16$ & $6.00 \pm 0.20$ & $8.16 \pm 0.38$ & $3.24 \pm 0.23$ \\
& $(0.04-2.61)$ & $(0.82-15.50)$ & $(1.31-35.10)$ & $(0.41-59.80)$ \\
Height $(\mathrm{m})$ & & & & $4.02 \pm 0.14$ \\
Mean* & $0.46 \pm 0.15$ & $6.15 \pm 0.13$ & $9.30 \pm 0.24$ & $(0.30-26.80)$ \\
& $(0.01-1.40)$ & $(1.49-10.73)$ & $(2.00-20.50)$ & \\
\hline
\end{tabular}

\footnotetext{
*Values are mean \pm S.E
} 
Am. J. Agri. \& Biol. Sci., 6 (2): 6 (2): 256-260, 2011

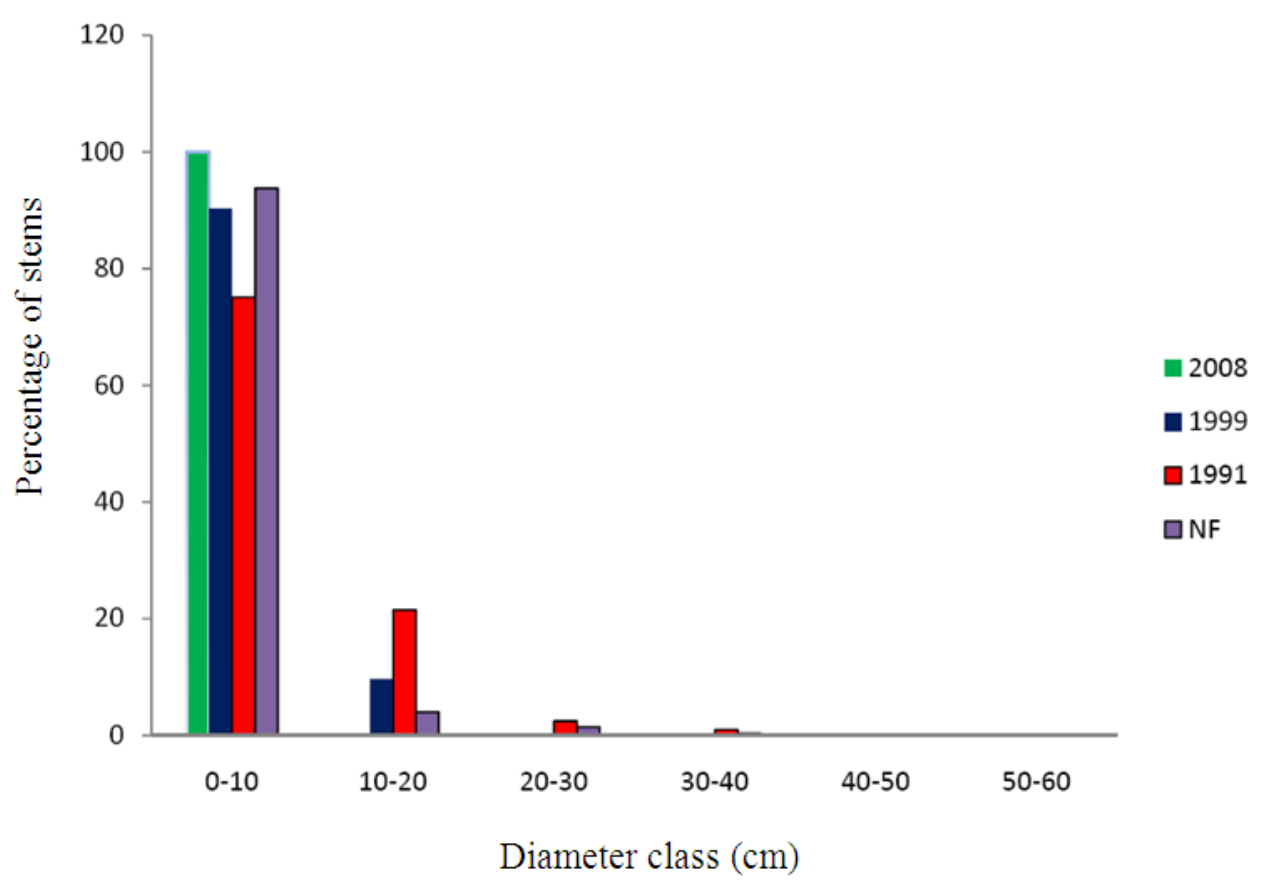

Fig. 1: Percentage of stands in different size class distribution of Dbh on the study plot at UPM Bintulu Sarawak Campus, Sarawak, Malaysia. Intervals of Dbh class were $10 \mathrm{~cm}$

Height: The mean height of Plots 1999 and 1991 were 46 and $60 \%$, respectively of the Plot NF with significant differences, despite Plot NF having the tallest tree $(26.80 \mathrm{~cm})$ in the study area. Plot 2008 has the shortest stand as compared to all the study plots while Plot 1991 has the tallest tree mean height. The mean height $(\mathrm{m})$ distribution among the study plots are shown in Table 1.

\section{DISCUSSION}

When compared to the natural regenerating secondary forest plot, older forest rehabilitation project site plots such as Plot 1991 showed better structural characteristics in terms of mean height, diameter and basal area with significant differences in terms of diameter size class. However, these values obtained still reflects the typical structural feature of secondary forest with lower canopy height, basal area and high total stem density but low density of trees more than $10 \mathrm{~cm}$ Dbh. Whitmore (1998) reported that a typical tropical lowland evergreen rain forest usually has $25-45 \mathrm{~m}$ of canopy height and emergent trees to $60-80 \mathrm{~m}$ tall. In addition, Brearley et al. (2004) reported the mean tree height of old secondary forest to be $19.0 \mathrm{~m}$ as compared to 22.1 in a primary forest at Barito Ulu, Central Kalimantan while Okuda et al. (2003) also recorded mean canopy height of
$27.4 \mathrm{~m}$ and 24.8 in a primary forest and regenerating forest at Pasoh Forest Reserve, Negeri Sembilan, Malaysia. The highest height obtained from our study plots at Plot NF (26.8 m) and Plot 1991 (20.5 m) is comparable to those means in an old secondary forest reported for 41-55 years old stand (Okuda et al., 2003; Brearley et al., 2004) with an overall low mean canopy height.

The mean Dbh in all the study plots is relatively small in comparison to other more matured or older secondary forest. In terms of Dbh size, the study plots are at an early stage of successional recovery. However, the lack of bigger size Dbh tree in Plot NF is due to removal legally or illegally prior to 1987 where the area was once a logging concession area. For example, in the secondary forest of Ayer Hitam Forest Reserve, Selangor, Malaysia, the mean Dbh was $20.8 \mathrm{~cm}$ and in a 15-year old secondary forest, Costa Rica the Dbh ranges from 20-25 cm (Brown and Lugo, 1990). In addition, more than $75 \%$ of the stems fall less than 10 $\mathrm{cm}$ Diameter Size Class. These are common features of regenerating and some primary forests as reported by Manokaran and Kochummen (1987) and Okuda et al. (2003). The frequency of larger tree increased with age in the rehabilitated forest project site plots. These mimic the characteristics of typical secondary forest of high total stem density but low density of trees less than $10 \mathrm{~cm}$ Dbh. 
Generally, the basal areas for all the plots were higher after extrapolation to a hectare basis. Higher basal area was due to the high density planting in this rehabilitation technique. Basal area reported for tropical forest ranges from 28-52 $\mathrm{m}^{2} \mathrm{~h}^{-1}$ (Swaine et al., 1987), Ayer Hitam Forest Reserve, Selangor, Malaysia was $21.1 \mathrm{~m} 2 \mathrm{~h}^{-1}$, Timbah Virgin Jungle Reserve, Sabah, Malaysia was $38.4-39.8 \mathrm{~m}^{2} \mathrm{~h}^{-1}$. However, it is worth to note that the mean basal area in Plot 1991 was significantly higher than in Plot NF. This should be taken with caution in arriving at a conclusion about the forest structure as suggested by Brown and Lugo (1990). They cautioned that the process of vegetation ageing involves rapid structural change such as basal area and volume may be similar to mature forest. The process of maturing involves changes in the quality of structure i.e., the density and chemistry of wood and many of these quantitative changes are accompanied by changes in species composition.

The accelerating natural regeneration technique to rehabilitate degraded forest area has been proven to accelerate some aspects of the structural characteristics such as the overall mean basal area (61\%), mean Dbh $(56 \%)$ and mean height (60\%) of the trees as compared to the adjacent natural regenerating secondary forest despite having lack of similarity in the diameter class distribution. High density planting of 3 seedlings per meter square in the site elucidated the higher basal area and taller trees obtained in the study. The basis for tree survival is to reach the highest ground for sunlight in a very competitive environment. Over time, after intense competition among the trees, the fittest survive and death of trees provides more space for radial growth. Miyamoto et al. (2007) reported that forests under stress are expected to exhibit stronger reactions in forest structure and physiognomy. For example, tropical heath forests which are subjected to nutrient and water stress is characterized by short stature, slender trunks, thick leaves and low species richness (Whitmore, 1984; Richards, 1996). These are associated with drought (Brunig, 1974), heat load (Whitmore, 1998), nutrient deficiency and anti-herbivore defence (Turner, 1994). It is reasonable to suggest that trees planted using accelerating natural regeneration technique perform better in terms of structural features after 18 years, though they are yet to fully recover showing climax forest structural features which indicate the health status of each of the study plots.

\section{CONCLUSION}

It can be concluded that after 18 years, rehabilitated forest showed better structure in comparison to the adjacent natural regenerating secondary forest. The assessment on the forest structure provides an indication of the biodiversity and forest health of the rehabilitated forest. The acceleration natural regeneration technique to rehabilitate degraded forest area has enhanced the means of structural parameters such as Dbh, height and basal area as compared to the natural regenerating secondary forest. This can help to promote the reforestation and restoration activities at degraded forest. Overall, rehabilitated forest areas have yet to recover in terms of size and height.

\section{ACKNOWLEDGMENT}

The researchers would like to thank the management and field staff of the Universiti Putra Malaysia Bintulu Sarawak Campus for their kind support, assistance and cooperation during this study. This research was supported by the research grant from the Mitsubishi Corporation, Japan.

\section{REFERENCES}

Alfred, R., K.P. Hue, L.S. Khee and R. Alfred, 2010. The importance of maintaining a proper database on forest restoration program for orangutans in Borneo. American J. Env. Sc., 6: 137-151. DOI: 10.3844/ajessp.2010.137.151

Ainuddin, N.A. and K. Goh, 2010. Effect of forest fire on stand structure in Raja Musa Peat Swamp Forest Reserve, Selangor, Malaysia. J. Environ. Sci. Technol., 3: 56-62.

Brearley, F.Q., S. Prajadinataa, P.S. Kidda, J. Proctor and Suriantata, 2004. Structure and floristics of an old secondary rain forest in Central Kalimantan, Indonesia and a comparison with adjacent primary forest. For. Ecol. Manage., 195: 385-397. DOI: 10.1016/j.foreco.2004.02.048

Brown, S. and A.E. Lugo, 1990. Tropical secondary forests. J. Trop. Ecol., 6: 1-32. DOI: 10.1017/S0266467400003989

Brunig, E.F., 1974. Ecological studies in the kerangas forests of Sarawak and Brunei. 1st Edn., Borneo Literature Bureau for Sarawak Forest Department, Malaysia, pp: 237.

Manokaran, N. and K.M. Kochummen, 1987. Recruitment, growth and mortality of tree species in a lowland dipterocarp forest in Peninsular Malaysia. J. Trop. Eco., 3: 315-330. DOI: 10.1017/S0266467400002303

Miyamoto, K., J.S. Rahajoe, T. Kohyama and E. Mirmanto, 2007. Forest structure and primary productivity in a Bornean heath forest. Biotropica, 39: $\quad 35-42 . \quad$ DOI: $\quad 10.1111 / \mathrm{j} .1744-$ 7429.2006.00231.x 
Miyawaki, A., 1999. Creative ecology: Restoration of native forests by native trees. Plant Biotech., 16: 15-25.

Okuda, T., M. Suzuki, N. Adachi, E.S. Quah and N.A. Hussein et al., 2003. Effect of selective logging on canopy and stand structure and tree species composition in a lowland dipterocarp forest in Peninsular Malaysia. Forest Ecol. Manage., 175: 297-320. DOI: 10.1016/S0378-1127(02)00137-8

Richards, P.W., 1996. The Tropical Rain Forest: An Ecological Study. Cambridge University Press, UK., ISBN-10: 0521421942, pp: 575.

Swaine, M.D., D. Lieberman and F.E. Putz, 1987. The dynamics of tree populations in tropical forest: A review. J. Trop. Ecol., 3: 359-366. DOI: $10.1017 / \mathrm{S} 0266467400002339$
Turner, I.M., 1994. Sclerophylly: primarily protective? Funct. Ecol. 8: 669-675. DOI: 10.2307/2390225

Verchot, L.V. and E. Petkova, 2009. The state of REDD negotiations consensus points, options for moving forward and research needs to support the process. Center for International Forestry Research (CIFOR) Bogor, Indonesia. http://www.forestforclimate.org/attachments/490_ UNREDD-state_of_REDD_negotiations.pdf

Whitmore, T.C., 1984. Tropical Rain Forests of the Far East. 2nd Edn., Clarendon Press, USA., ISBN-10: 0198541368 , pp: 352.

Whitmore, T.C., 1998. An Introduction to Tropical Rain Forests. 2nd Edn., Oxford University Press, USA., ISBN-10: 019850148X, pp: 282. 